\title{
The Effect of non-Surgical Periodontal Treatments on the Severity of Arthritis Rheumatoid
}

\author{
Narjes Akbari ${ }^{1}$, Vajehallah Raeesi ${ }^{2}$, Ahmadreza Sebzari ${ }^{3}$, Marziyeh Talaei ${ }^{4}$, Hakimeh MalakiMoghadam ${ }^{5}$, Elham Atabati*6 \\ ${ }^{1}$ Associate Professor of oral medicine, Faculty of dentistry, Birjand University of medical Sciences, Birjand, Iran. \\ ${ }^{2}$ Assistant Professor, Department of internal medicine, Birjand University of medical Sciences, Birjand, Iran \\ ${ }^{3}$ Assistant Professor, Clinical Researsh Development unit, Valiasr Hospital, Birjand University of medical Sciences, Birjand, Iran \\ ${ }^{4}$ Student Research Committee, Birjand University of Medical Sciences, Birjand, Iran \\ ${ }^{5} \mathrm{MSc}$ in biostatistics, Infectious Diseases Research Center, Birjand University of Medical Sciences, Birjand, Iran \\ ${ }^{6}$ Assistant Professor, Clinical Researsh Development unit, Valiasr Hospital, Birjand University of medical Sciences, Birjand, Iran
}

*Corresponding Author: Elham Atabati, Assistant Professor, Clinical Researsh Development unit, Valiasr Hospital, Birjand University of medical Sciences, Birjand, Iran.

Received date: April 17, 2021; Accepted date: April 28, 2021; Published date: May 18, 2021

Citation: N Akbari, A Sebzari, M Talaei, H M Moghadam, E Atabati et al. (2021) The Effect of non-Surgical Periodontal Treatments on the Severity of Arthritis Rheumatoid. Clinical Research and Clinical Trials. 3(4); DOI: 10.31579/2693-4779/038

Copyright: (C) 2021 Elham Atabati. This is an open access article distributed under the Creative Commons Attribution License, which permits unrestricted use, distribution, and reproduction in any medium, provided the original work is properly cited.

\section{Abstract}

Background: periodontal disease with alveoli bone degeneration and losing teeth is seen in many people, including those with arthritis rheumatoid.

Objective This study aims to evaluate the effect of non-surgical periodontal treatments on the severity of arthritis rheumatoid.

Methods: this randomized control clinical trial was conducted on 60 patients who concurrently had arthritis and mild to moderate periodontitis. Patients divided into three groups of 20 subjects (group $\mathrm{C}$ had tooth cleaning and antibiotic therapy, group B had only tooth cleaning and group A was control). DAS28 questionnaire was filled out for all three groups at the beginning of the study. After ending the treatment and improvement, patients were examined in days 45 and 90 in terms of improvement indicators for arthritis rheumatoid. Data were finally analyzed by SPSS18.

Results: the highest reduction rate of ESR, DAS28, CRP and RF was in different time periods in tooth cleaning intervention +antibiotic group and then, teeth cleaning group. The lowest reduction was seen in control group. RF, CRP and DAS28 indices showed significant differences in different time periods in tooth cleaning group and tooth cleaning+ antibiotic group $(\mathrm{P}<0.05)$.

Conclusion: non-surgery periodontal treatment and RA indices, without considering the medicines used for treatment, had positive effect on the treatment of this disease.

Keywords: arthritis rheumatoid; tooth cleaning; antibiotic

\section{Introduction}

World Health Organization (WHO) considers oral hygiene as a necessity and a part of public health in lifetime and states that the health impacts the quality of life. Besides, some chronic diseases are related with oral and dental problems; therefore, paying attention to this issue is one of the programs of $\mathrm{WHO}$ in preventing chronic disease and promoting health [1].

More than several thousand people suffer periodontal diseases around the world. The prevalence of these diseases are high, even higher than tooth caries [2]. There are various types of periodontal diseases that their common feature is changing the ideal condition of periodontium and providing a ground for destruction [3]. Periodontal disease are the major cause of losing permanent teeth. Inflammation, bleeding, gingivitis, bone degradation, tooth displacement, pain and other problems are other sideeffects of periodontal diseases [4].

Various studies have shown that demographic factors such as age and gender, socio-economic conditions, inflammatory factors, systemic conditions, drugs and other factors lead to periodontal disease [5].

The research showed that from among 10 people, 9 people suffer periodontal disease during their lifetime [6]. Based on the research about periodontitis and systemic diseases, there is a relationship between periodontal diseases and arthritis rheumatoid, cardiovascular disease and mellitus diabetes. Similar cases have been reported in pathobiology of periodontitis and arthritis rheumatoid [7, 8]. 
Arthritis rheumatoid is a mild and chronic autoimmune disease but it can be severe and paralyzing. This disease occurs around the world and approximately $1 \%$ of the world population suffer it. The prevalence of this disease in women is 3 times of men. This disease occur in decades four and five of life. $3 \%$ of US population suffer this disease to some degree and more than 200,000 new cases are diagnosed every year [9].

The definite and common role of the immune response is clear in this disease and periodontitis. Although the etiology of these two diseases are different, the basic pathogens mechanism is similar in all of them. On the other hand, there is a significant relationship between these two diseases which is a reflection of a basic disorder in inflammatory reaction of these people. There are evidence that show arthritis rheumatoid is one of the causes of periodontitis [10]. Patients susceptible to arthritis rheumatoid may suffer periodontitis in the presence of periodontal pathogens and suitable environment. Soory studied the definite role of immune reaction in diabetes, arthritis rheumatoid and periodontal disease and confirmed the relationship between these diseases and periodontal diseases. Since there is a similarity between periodontitis pathobiology and arthritis rheumatoid and the role of immune reaction is proved in these diseases [11], as well as consulting and referring these patients by physicians to dentists and high prevalence of them, it is vital to study and prevent the problems related to these diseases. Therefore, this research aims to study the role of periodontal diseases on the severity of arthritis rheumatoid in order to increase the awareness about prevention and provide services.

\section{Materials and Methods}

This is a randomized clinical trial with control.

\begin{tabular}{|c|c|c|c|c|c|}
\hline $\begin{array}{l}\text { Study group } \\
\text { Study time }\end{array}$ & $\begin{array}{l}\text { Control } 1 \\
=20 \\
\mathrm{X} \pm \mathrm{SD}\end{array}$ & $\begin{array}{l}\text { Tooth-cleaning2 } \\
\mathrm{N}=20 \\
\mathrm{X} \pm \mathrm{SD}\end{array}$ & $\begin{array}{l}\text { Tooth cleaning } \\
\text { +antibiotic } 3 \\
\mathrm{~N}=20 \\
\mathrm{X} \pm \mathrm{SD}\end{array}$ & ANOVA result & Tukey test \\
\hline \begin{tabular}{ll}
\multicolumn{3}{l}{ Before intervention 1} \\
$45 \quad$ days & after \\
intervention 2 & \\
$90 \quad$ days & after \\
intervention 3 &
\end{tabular} & $\begin{array}{l}5.54 \pm 1.03 \\
5.39 \pm 1.06 \\
5.24 \pm 1.11\end{array}$ & $\begin{array}{l}4 \pm 1.64 \\
3.49 \pm 1.38 \\
2.86 \pm 1.09\end{array}$ & $\begin{array}{l}4.64 \pm 0.97 \\
3.77 \pm 0.77 \\
2.96 \pm 0.86\end{array}$ & $\begin{array}{l}F=7.67, P=0.001 \\
F=17.4, P<0.001 \\
F=34.4, P<0.001\end{array}$ & $\begin{array}{l}1,2 \mathrm{P}=0.001 \\
1,2,3 \mathrm{P}<0.001 \\
1,2,3 \\
\mathrm{P}<0.001\end{array}$ \\
\hline $\begin{array}{l}\text { Repeated variance } \\
\text { analysis result }\end{array}$ & $\begin{array}{l}\mathrm{F}=32.1 \\
\mathrm{P}<0.001\end{array}$ & $\begin{array}{l}\mathrm{F}=52.9 \\
\mathrm{P}<0.001\end{array}$ & $\begin{array}{l}\mathrm{F}=140.7 \\
\mathrm{P}<0.001\end{array}$ & & \\
\hline Bonferoni test result & $\begin{array}{l}1,2 \mathrm{P}<0.001 \\
1,3 \mathrm{P}<0.001 \\
2,3 \mathrm{P}=0.002\end{array}$ & $\begin{array}{l}1,2 \mathrm{P}<0.001 \\
1,3 \mathrm{P}<0.001 \\
2,3 \mathrm{P}<0.001\end{array}$ & $\begin{array}{l}1,2 \mathrm{P}<0.001 \\
1,3 \mathrm{P}<0.001 \\
2,3 \mathrm{P}<0.001\end{array}$ & & \\
\hline
\end{tabular}

Table 1: comparing mean of DAS in three studied groups, before, 45 days and 90 days after intervention
Based on following table data, mean ESR showed significant reduction after intervention in three groups. This difference was significant in different time period in all three groups. There was no significant
The samples were selected voluntarily and randomly from among those patients who visited Valiasr educational hospital in Birjand.

After data collection, data were entered in SPSS software version 18 and by providing descriptive statistics and using repeated variance tests, Bonferoni test, chi-square test, and ANOVA, they were analyzed in $\mathrm{a}=0.05$ level. In the case of lack of data normality distribution, Wilcoxon, Freidman, Kruskal-Wallis and Mann-Whitney non-parametric tests were used.

The private information of the studied people remained confidential.

Since tooth cleaning is not considered in the care protocol of arthritis rheumatoid patients, delaying it in the control group was permissible. Periodontal treatment was done for control group at the end of work.

\section{Results}

This study was conducted on 60 patients in three groups of 20 subjects including control, tooth-cleaning, and tooth cleaning+ antibiotic groups. From among 60 patients in this study, except one men in tooth-cleaning group, all other subjects were women and both groups were same in terms of gender (Fisher exact test=1). Mean age in both groups had not significant statistical difference.

Based on the above table data, there was no significant different in mean age of three studied groups and three groups were same in terms of age.

Based on the following table data, mean DAS showed significant difference after intervention in all three groups. This reduction had significant difference among the three groups in the studied periods $(\mathrm{P}<0.05)($ table 1).

difference before intervention and 45 days after intervention in mean ESR of three groups but ESR was significantly lower in tooth cleaning and tooth cleaning+ antibiotics groups than control group $(\mathrm{P}<0.001)$ (table 2$)$.

\begin{tabular}{|c|c|c|c|c|c|c|}
\hline & $\begin{array}{l}\text { Study group } \\
\text { Study time }\end{array}$ & $\begin{array}{l}\text { Control (A) } \\
\mathrm{N}=20 \\
\mathrm{X} \pm \mathrm{SD}\end{array}$ & $\begin{array}{l}\text { Tooth-cleaning } \\
\text { (B) } \\
\mathrm{N}=20 \\
\mathrm{X} \pm \mathrm{SD}\end{array}$ & $\begin{array}{l}\text { Tooth cleaning } \\
\text { +antibiotic }(\mathrm{C}) \\
\mathrm{N}=20 \\
\mathrm{X} \pm \mathrm{SD}\end{array}$ & ANOVA result & Tukey test \\
\hline ESR & Before intervention (1) & $32.15 \pm 13$ & $24.75 \pm 11.6$ & $32.75 \pm 9.6$ & $\mathrm{~F}=2.96, p=0.06$ & NS \\
\hline
\end{tabular}




\begin{tabular}{|c|c|c|c|c|c|c|}
\hline & $\begin{array}{l}45 \text { days after intervention( } 2 \text { ) } \\
90 \text { days after intervention (3) } \\
\text { Repeated variance analysis result }\end{array}$ & $\begin{array}{l}26.75 \pm 3.10 \\
24.3 \pm 10.8 \\
F=8.85 \\
P=0.001\end{array}$ & $\begin{array}{l}19.45 \pm 10.4 \\
13.65 \pm 7.3 \\
F=22.4 \\
P<0.001\end{array}$ & $\begin{array}{l}25.25 \pm 8.8 \\
18 \pm 7.7 \\
\mathrm{~F}=44.4 \\
\mathrm{P}<0.001\end{array}$ & $\begin{array}{l}F=30.5, p=0.015 \\
F=7.54, p=0.001\end{array}$ & $\begin{array}{l}\text { NS } \\
\text { A,B,C P }<0.001\end{array}$ \\
\hline $\mathrm{RF}$ & $\begin{array}{l}\text { Before intervention (1) } \\
45 \text { days after intervention ( } 2) \\
90 \text { days after intervention (3) } \\
\text { Repeated variance analysis result }\end{array}$ & $\begin{array}{l}12.65 \pm 3.1 \\
12.6 \pm 3.14 \\
12.57 \pm 3.16 \\
F=0.22, P=0.81\end{array}$ & $\begin{array}{l}11.72 \pm 3.2 \\
11.47 \pm 3.2 \\
10.1 \pm 2.7 \\
\mathrm{~F}=18.38 \\
\mathrm{P}<0.001\end{array}$ & $\begin{array}{l}12.27 \pm 2.7 \\
10 \pm 1.9 \\
8.78 \pm 2.3 \\
F=2.19, P<0.001\end{array}$ & $\begin{array}{l}F=0.48, P=0.62 \\
F=4.35, P=0.013 \\
F=9.9, P<0.001\end{array}$ & $\begin{array}{l}\text { NS } \\
\text { A,C P }=0.013 \\
\text { A,B P }=0.015 \\
\text { A,C P }<0.001\end{array}$ \\
\hline
\end{tabular}

Table 2: comparing mean ESR in three studied groups before, 45 days and 90 days after intervention

Mean CRP showed no significant difference at three studied time periods but there was significant reduction in tooth cleaning and tooth cleaning+ antibiotics groups after intervention in CRP mean. This difference showed significant statistical difference at all time periods $(\mathrm{P}<0.05)($ table 2).

Based on the following table, RF index in control group did not show significant statistical difference in three study time periods but in the tooth cleaning and tooth cleaning+ antibiotics groups, mean RF showed significant reduction after intervention and this reduction was also significant in different time periods. Before intervention, RF index was same in all three groups but 45 and 90 days after intervention, RF was significantly higher in control group than two other groups $(\mathrm{P}<0.01)$ (table 2).

Mean DAS changes in all study time periods showed higher reduction in tooth cleaning + antibiotic group than tooth cleaning group and also in tooth cleaning group than control group. This difference between mean of DAS of groups was statistically significant $(\mathrm{P}<0.01)$

Although the highest ESR reduction was in tooth cleaning + antibiotic and then, tooth cleaning groups and the lowest ESR reduction was in control group, but these differences were not statistically significant $(\mathrm{P}>0.05)$ Although the highest CRP reduction was in tooth cleaning + antibiotic and then, tooth cleaning groups and the lowest CRP reduction was in control group. This was statistically significant $(P>0.05)$ although the highest RF reduction was in tooth cleaning + antibiotic and then, tooth cleaning groups and the lowest RF reduction was in control group. This was statistically significant in intervention and control groups $(\mathrm{P}>0.05)$

\section{Discussion}

Arthritis rheumatoid is the most common chronic and inflammatory disease of joint that can lead to the degeneration of joints, disability and motor limitation of patients. About $30 \%$ of those who suffer arthritis rheumatoid may suffer secondary Sjögren syndrome that is an autoimmune exocrinopathy. In this condition, due to the reduction of salvia and fry mouth and as a result, reducing the antibacterial effects of salvia, periodontal disease intensifies [29]. Periodontitis is the most common oral disease; it is an inflammatory and degenerating disease of tooth tissues that occurs by microorganisms like Porphyromonas gingivalis. In a person who have immune suppression, poor defense and safety caused by chronic disease like arthritis rheumatoid, gum inflammation is more common and sever [30]. Therefore, this study was conducted to examine the effect of non-surgical periodontal treatments on the severity of arthritis rheumatoid.
According to this study, all 90 patients were women expect one. In different studies, the prevalence of this disease is higher in women than men [31, 32]. Lipsky PE has reported in Harrison book that arthritis rheumatoid is three times higher in women than men [33].

Based on the results of this study, in all three groups, mean DAS showed significant reduction after intervention. This reduction indicated significant statistical difference in all three groups in the study time periods $(\mathrm{P}<0.05)$ but mean changes of DAS reduced more in tooth cleaning+ antibiotic than tooth cleaning and also in tooth cleaning than control group.

These findings were consistent with previous findings [34, 35] that indicate the positive effect of periodontal treatment on RA condition. Oritz et.al [38] studied the effect of periodontal disease treatment on the severity of arthritis rheumatoid and reported that periodontal treatment reduces DAS28 in these patients, such that DAS28 showed more reduction in tooth cleaning method than control group and this reduction was statistically significant. Their results were consistent with the present study.

Ebersole JL et.al stated that periodontal disease is a systemic inflammatory disease and periodontal treatment only reduces inflammatory products. Therefore, periodontal treatment leads to the reduction of inflammatory markers in arthritis rheumatoid patients. Another explanation is that eliminating periodontal pathogens using tooth cleaning and extending the root reduces the encounter between bacteria and their toxin with joints structure, and consequently, it improves RA conditions [37]. Most exclusive traits of microorganism to become a suitable genetic host for arthritis rheumatoid are present in those microorganisms that are related to periodontitis [11].

The results of this study showed that there was no significant difference in mean ESR before intervention and 45 days after intervention among three groups but in 90 days after intervention, ESR was significantly lower in tooth cleaning group and tooth cleaning+ antibiotic group than control group $(\mathrm{P}<0.001)$. The highest ESR reduction was in tooth cleaning + antibiotics group and then, tooth cleaning group. The lowest reduction was of ESR was in control group.

In Al-Katma et.al study, ESR improved \%76.4 in group with training and tooth cleaning but it improved \%16.7 in control group. There was a significant difference between both groups in terms of ESR that after 8 weeks, it showed the effect of tooth cleaning on improving EST. This is consistent with our study [35]. 
In Juliana Riberio et.al study (2005) about the effect of periodontal disease on the severity of arthritis rheumatoid, periodontal treatment was an effective factor in reducing the severity of arthritis rheumatoid such that most people with tooth cleaning showed lower ESR than control group. This difference in mean ESR was significant in both groups [34].

Amoxicillin and metronidazole were used in periodontal treatment. The used dose of antibiotics was similar to other studies [38-40]. These studies showed the useful effect of systematic prescribing of antibiotics as supplement and reported no serious side-effect except mild intestinal problems.

Some clinical studies showed that non-surgical treatment along with using systemic antibiotic is useful [41]. In the present study, using antibiotics along with tooth cleaning had the higher effect on improving the periodontal condition as well as arthritis rheumatoid.

The results of the current study showed that there is no significant difference in CRP in three studies time periods in the control group but there was a significant reduction in mean CRP after intervention in tooth cleaning group and tooth-cleaning+ antibiotics group. This difference was statistically different $(\mathrm{P}<0.05)$. The highest $\mathrm{CRP}$ reduction in different time period in was tooth cleaning + antibiotics followed by tooth cleaning group. The lowest reduction of CRP was in control group and this difference was statistically different $(\mathrm{P}<0.05)$.

In Heidari et.al study [42] about the relationship between serum CRP concentration with arthritis rheumatoid, it was stated that there is a direct relationship between CRP concentration in serum and arthritis rheumatoid and the severity of disease can be estimated in some patients based on serum CRP.

Marcia et.al [43] studied the relationship between periodontal disease with arthritis rheumatoid and effect of periodontal treatments on arthritis. They reported that groups with periodontal treatment showed strong reduction in all parameters (periodontal indices and RA). They stated that although the correlation between periodontal disease and arthritis rheumatoid is not clear yet but periodontal treatment is necessary for patients with RA.

Al-Katma [35] stated that periodontal inflammation produces globulins, plasma proteins (like hepatoglobulis), C-reactive protein and fibrinogen. The improvement of symptoms and indices related to RA (CRP, DAS28, ESR) in periodontal treatment group compared to control group may be due to the reduction of inflammatory products in the blood after periodontal treatment. In D'Aiuto et.al study [44], two months after SRP and plaque control, the significant reduction in CRP and interlukin-6 was seen in periodontal treatment group that is consistent with our results.

The findings of other studies [22, 45] also indicated the effect of periodontal treatment on reducing CRP that are consistent with the current study results.

Based on the results of its study, there was no significant difference in mean RF in control group in three time period but RF showed significant reduction in tooth cleaning group and tooth cleaning+ antibiotic group after intervention. RF was same in all three groups before intervention but it was significantly higher in control group 45 days and 90 days after intervention $(\mathrm{P}<0.01)$.

In Juliana Riberio et.al study [34], RF reduced in group with periodontal treatment compared to control group but this difference was not statistically different. This is not consistent with the results of our study.
The results of Khare N1 et.al study (2016) are consistent with our results such that group B who received periodontal non-surgical treatments, improved significantly in terms of periodontitis and RA factors. The symptoms and severity of RA also decreased [21].

One advantage of this study was comparing tooth cleaning with tooth cleaning along with antibiotic therapy in arthritis rheumatoid patients. Similar studies $[35,36]$ have only dealt with the effect of tooth cleaning.

\section{Conclusion}

1- The highest reduction of ESR, DAS28, CRP and RF in different time periods was in tooth cleaning+ antibiotic group followed by tooth cleaning group. The lowest reduction was in control group.

2- Based on the results of this study, RF and CRP showed no significant statistical difference in three time periods in control group but it showed significant reduction in tooth cleaning, and tooth cleaning + antibiotics groups after intervention in different time periods $(\mathrm{P}<0.05)$.

3- Mean DAS28 showed significant difference after intervention in all three studied groups. This reduction showed statistical significant difference in three groups at different time periods.

4- Before intervention and 45 days after intervention, there was no significant difference in mean ESR of all three groups but 90 days after intervention. ESR was significantly lower in tooth cleaning and tooth cleaning+ antibiotics group than control group $(\mathrm{P}<0.001)$.

Clinical Trials Registry: The trial identification code is IRCT20180613040084N1.

Funding: This work received support from Birjand University of medical Sciences, Birjanad, Iran.

Financial Support: This paper is extracted from thesis of Ms. Marzieh Talaee, dentistry student of Birjand University of medical sciences under ir.bums.REC.1396.353 number.

Disclosure statement: The authors have declared no conflicts of interest

Authors Contribution: Elham Atabati and Narjes Akbari conceived of the presented idea. Marziyeh Talaei developed the theory and performed the computations. Vajehallah Raeesi and Ahmadreza Sebzari verified the analytical methods. Hakimeh MalakiMoghadam analyzed data. Elham Atabati encouraged Marziyeh Talaei to investigate and supervised the findings of this work. All authors discussed the results and contributed to the final manuscript.

Acknowledgement The authors would like to appreciate the research deputy of dentistry faculty, Birjand medical sciences university that provided required facilities for this research.

\section{References}

1. Shamsi M, Hidarnia A, Niknami SH, Atarha M, Jadidi R. (2013) Oral health of pregnant women in Arak, Iran. Payesh. 12 (4) :355365

2. Gherunpong S, Tsakos G, Sheiham A. (2006) A sociodental approach to assessing dental needs of children: concept and models. International Journal of Paediatric Dentistry.16(2):81-8.

3. Krishna KB, Raju PK, Chitturi RR, Smitha G, Vijai S, Srinivas B. (2014) Prevalence of gingival enlargement in Karnataka school going children. Journal of international oral health: JIOH.6(1):106. 
4. Nanaiah KP, Nagarathna D, Manjunath N. (2013) Prevalence of periodontitis among the adolescents aged 15-18 years in Mangalore City: An epidemiological and microbiological study. Journal of Indian Society of Periodontology.17(6):784.

5. Anegundi RT, Sudha P, Nayak UA, Peter J. (2006) Idiopathic gingival fibromatosis: a case report. Hong Kong Dent J.3(1):53-7.

6. Borrell LN, Burt BA, Warren RC, Neighbors HW. (2006) The role of individual and neighborhood social factors on periodontitis: the third National Health and Nutrition Examination Survey. Journal of periodontology.77(3):444-53.

7. Albandar JM. (1990) Some predictors of radiographic alveolar bone height reduction over 6 years. Journal of Periodontal Research.25(3):186-92.

8. Schmitz M, Guedes L, Costa L, Macedo P, Caldas C, Medeiros D, et al, editors. (2008) Disease activity and functional status thresholds according to the Patients Acceptable Symptom State (PASS) of rheumatoid arthritis Brazilian patients. arthritis and rheumatism.2 (3): 86-92.

9. Gleissner C, Willershausen B, Kaesser U, Bolten W. (1998) The role of risk factors for periodontal disease in patients with rheumatoid arthritis. European journal of medical research.3(8):387-92.

10. Bakhtiari S, Taheri J, Abbasi F. (2009) Association between rheumatoid arthritis and moderate to severe periodontitis in Iranian adults. Journal of Dentistry of Tehran University of Medical Sciences.6(3):145-9.

11. Sorry M. (2002) Hormone mediation of immune responses in the progression of diabetes, rheumatoid arthritis and periodontal diseases. Current Drug Targets-Immune, Endocrine \& Metabolic Disorders.2(1):13-25.

12. Taheri M, Saghafi M, Najafi M, Radvar M, Marjani S, Javanbakht A, et al. (2011) Investigation of Periodontal Conditions in Patients with Rheumatoid Arthritis. Journal of Mashhad Dental School.35(4):283-8.

13. Anderson D. (2005) Harrison's principles of internal medicine. AAN Enterprises.

14. Bingham III CO, Moni M. (2013) Periodontal disease and rheumatoid arthritis: the evidence accumulates for complex pathobiologic interactions. Current opinion in rheumatology.25(3):345.

15. Poor T. (2010) Comparison of clinical course, manifestations and complications of rheumatoid arthritis among men and women referred to two medical centers during 2006-2007: Army University of Medical Sciences. 2 (3): 45-52.

16. Kawar N, Gajendrareddy PK, Hart TC, Nouneh R, Maniar N, Alrayyes S. (2011) Periodontal disease for the primary care physician. Disease-a-month: DM;57(4):174-83.

17. Newman MG, Takei H, Klokkevold PR, Carranza FA. (2018) Newman and Carranza's Clinical Periodontology E-Book: Elsevier Health Sciences.

18. Garlet G, Cardoso C, Silva T, Ferreira B, Avila-Campos M, Cunha F, et al. (2006) Cytokine pattern determines the progression of experimental periodontal disease induced by Actinobacillus actinomycetemcomitans through the modulation of MMPs, RANKL, and their physiological inhibitors. Oral microbiology and immunology;21(1):12-20.

19. Andrade PF, Garlet GP, Silva JS, Fernandes PG, Milanezi C, Novaes Jr AB, et al. (2013) Adjunct effect of the antimicrobial photodynamic therapy to an association of non-surgical and surgical periodontal treatment in modulation of gene expression: a human study. Journal of Photochemistry and Photobiology B: Biology; 12(6):119-25.

20. Choi IA, Kim J-H, Kim YM, Lee JY, Kim KH, Lee EY, et al. (2016) Periodontitis is associated with rheumatoid arthritis: a study with longstanding rheumatoid arthritis patients in Korea. The Korean journal of internal medicine;31(5):977.

21. Khare N, Vanza B, Sagar D, Saurav K, Chauhan R, Mishra S. (2016) Nonsurgical Periodontal Therapy decreases the Severity of Rheumatoid Arthritis: A Case-control Study. The journal of contemporary dental practice;17(6):484-8.

22. Monsarrat P, Vergnes J-N, Cantagrel A, Algans N, Cousty S, Kémoun P, et al. (2013) Effect of periodontal treatment on the clinical parameters of patients with rheumatoid arthritis: study protocol of the randomized, controlled ESPERA trial. Trials; $14(1): 253$.

23. Javadi F. (2012) Investigating the relationship between rheumatoid arthritis and periodontal disease.Qazvin University of Medical Sciences, Qazvin, Iran;5(2):85-90.

24. Susanto H, Nesse W, Kertia N, Soeroso J, Huijser van Reenen Y, Hoedemaker E, et al. (2013) Prevalence and severity of periodontitis in Indonesian patients with rheumatoid arthritis. Journal of periodontology;84(8):1067-74.

25. De Pablo P, Chapple IL, Buckley CD, Dietrich T. (2009) Periodontitis in systemic rheumatic diseases. Nature Reviews Rheumatology;5(4):218.

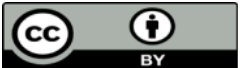

This work is licensed under Creative Commons Attribution 4.0 License

\section{To Submit Your Article Click Here: Submit Manuscript}

DOI: $10.31579 / 2693-4779 / 038$

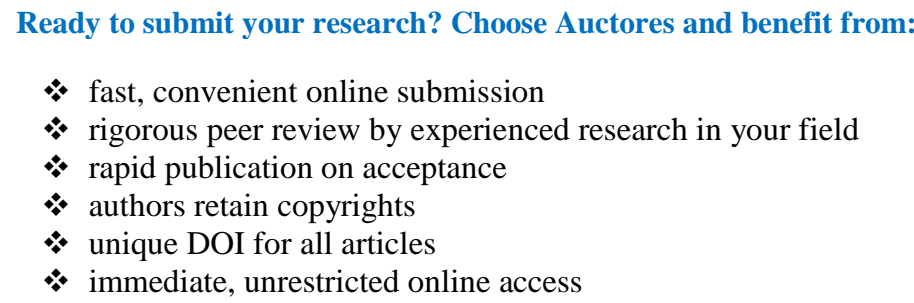

Ready to submit your research? Choose Auctores and benefit from:

* fast, convenient online submission

* rigorous peer review by experienced research in your field

* rapid publication on acceptance

* authors retain copyrights

* unique DOI for all articles

* immediate, unrestricted online access

At Auctores, research is always in progress.

Learn more www.auctoresonline.org/journals/clinical-research-andclinical-trials 